Research Paper

\title{
Comparison of Methods for the Extraction of DNA from Formalin-Fixed, Paraffin-Embedded Archival Tissues
}

\author{
Burcu Sengüven $^{1}{ }^{\bowtie}$, Emre Baris ${ }^{1}$, Tulin Oygur ${ }^{1}$, Mehmet Berktas $^{2}$ \\ 1. Department of Oral Pathology, Faculty of Dentistry, Gazi University, Ankara, Turkey; \\ 2. Pharmacoeconomy and Pharmacoepidemiology Research Center (PEPIRC), Yeditepe University, Istanbul, Turkey. \\ $\triangle$ Corresponding author: Dr. Burcu Sengüven, Department of Oral Pathology, Faculty of Dentistry, Gazi University. ANKARA 06510, \\ TURKEY. Telephone: +90 3122034384 Fax: +90312 2239226 E-mail: senguvenb@yahoo.com. \\ (C) Ivyspring International Publisher. This is an open-access article distributed under the terms of the Creative Commons License (http://creativecommons.org/ \\ licenses/by-nc-nd/3.0/). Reproduction is permitted for personal, noncommercial use, provided that the article is in whole, unmodified, and properly cited.
}

Received: 2014.02.15; Accepted: 2014.03.13; Published: 2014.03.27

\begin{abstract}
Aim: Discussing a protocol involving xylene-ethanol deparaffinization on slides followed by a kit-based extraction that allows for the extraction of high quality DNA from FFPE tissues.

Methods: DNA was extracted from the FFPE tissues of 16 randomly selected blocks. Methods involving deparaffinization on slides or tubes, enzyme digestion overnight or for 72 hours and isolation using phenol chloroform method or a silica-based commercial kit were compared in terms of yields, concentrations and the amplifiability.

Results: The highest yield of DNA was produced from the samples that were deparaffinized on slides, digested for 72 hours and isolated with a commercial kit. Samples isolated with the phenol-chloroform method produced DNA of lower purity than the samples that were purified with kit. The samples isolated with the commercial kit resulted in better PCR amplification.

Conclusion: Silica-based commercial kits and deparaffinized on slides should be considered for DNA extraction from FFPE.
\end{abstract}

Key words: DNA extraction, formalin fixed paraffin-embedded tissues.

\section{Introduction}

Formalin (HCHO)-fixed paraffin-embedded (FFPE) tissues have been globally used in pathology studies for decades. FFPE tissues are not only suitable for years of storage but also represent the largest available source of biological materials. The increasing interest in genetic disorders and the genetic bases of diseases has increased the value of FFPE tissues for molecular studies.

Many specific approaches to extracting DNA from FFPE tissues for use in molecular analyses, such as Polymerase Chain Reaction (PCR), real-time quantitative PCR, Single Nucleotide Pleomorphism (SNP) analyses and whole genome sequencing, have been reported. However, DNA extraction from FFPE tis- sues remains challenging. Many studies have sought to optimize the extraction of DNA from FFPE tissues. Mineral oil has been used for deparaffinization [1], high-temperature $0.1 \mathrm{M} \mathrm{NaOH}$ has been shown to increase the efficiency of DNA extraction [2], attempts to create fully automated methods of isolating DNA from FFPE tissues have been made [3], and a variety of commercial kits [4] and conventional phenol chloroform isolation [5] have been utilized for DNA extraction.

Future molecular studies are highly dependent on the quality and quantity of nucleic acid extracted from FFPE tissues. Extraction is a multistep process, and a large number of parameters are involved. The 
most important steps are the pre-extraction steps, which include the choice of fixative, the time of fixation, preservation before fixation, the period of storage, etc. The most amplifiable DNAs extracted from FFPE tissues are those that are fixed in $10 \%$ buffered-neutral formalin (the most commonly used fixative) or acetone [6]. Because the histological detail of acetone-fixed tissues is low, acetone fixation is not preferred for routine pathologic examinations [6]. In contrast, formalin fixation induces cross-linkages between DNAs and protein that produce serious problems for molecular studies that require amplification-quality nucleic acid [7].

A large number of formalin-fixed specimens are still being collected in the archives of pathology laboratories across the world. These specimens are not limited to human specimens; rather the genetic information of pathogens that play key roles in genetically related diseases is protected perfectly in paraffin blocks. Therefore, optimizations of the methods of extracting high-quality of DNA are critical.

In the present study, we report the results of a comparison of different methods of DNA extraction from FFPE specimens. The goal of this study was to discuss a protocol involving xylene-ethanol deparaffinization on slides followed by a kit-based extraction that allows for the extraction of high quality nucleic acid from FFPE tissues and high rates of amplification.

\section{Material and Methods}

\section{Tissue Selection and Processing}

DNA was extracted from the FFPE tissues of 16 randomly chosen archival dental follicle tissue blocks in the Gazi University Faculty of Dentistry, Department of Oral Pathology. None of the blocks were older than two years. All tissues had been fixed in $10 \%$ buffered neutral formalin (i.e., a solution with a minimum of $37 \%$ formaldehyde that was free from acid, Merck KGaA, Darmstadt, Germany), processed (Vacuum Automatic Tissue Processor, Sakura Finetechnical, Tokyo, Japan) and embedded manually (Paraplast ${ }^{\circledR}$ Highmelt Paraffin, Leica Microsystems $\mathrm{GmbH}$, Wetzlar, Germany). Because, cell counts per sections would influence the expected yield, hypercellular dental follicles which have distinct odontogenic epithelial rests were chosen.

The tissue-processing protocol consisted of 12 steps that occurred over 6 hours in conditions of continuous agitation, pressure, and vacuum.

Seven serial sections of 8-10-micrometer thickness per each sample were taken using a standard microtome (Leica SM2000 R Sliding Microtome,Wetzlar, Germany) with disposable DNA-RNA free blades. Half of the sections from each block were deparaffinized on glass $(n=16)$, the other half were collected directly to sterile $1.5 \mathrm{ml}$ microcentrifuge tubes $(n=16)$.

\section{Deparaffinization and digestion}

The sections were deparaffinized on glass by two changes of xylene and washed with descending concentrations of ethanol after incubation at $56 \mathrm{C}^{\circ}$ for 45 minutes. Tissues were dried at room temperature after washing in distilled water. Without letting the tissues over-dry, each section scraped into a $1.5 \mathrm{ml}$ microcentrifuge tube with a sterile scalpel.

The sections in tubes were deparaffinized with two pre-warmed xylene washes followed by $95 \%$, $75 \%$, and $50 \%$ ethanol rinses as previously described $[5,8]$. Briefly, the tissue pellets were dried at $37^{\circ} \mathrm{C}$.

All pellets were digested with $20 \mu$ l proteinase $\mathrm{K}$ $(20 \mathrm{mg} / \mathrm{ml}$ proteinase $\mathrm{K}$, Roche Diagnostics $\mathrm{GmbH}$, Mannheim, Germany) and $180 \mu \mathrm{l}$ digestion buffer (10 $\mathrm{mM}$ Tris-HCl, $\mathrm{pH}$ 8.0.100 mM EDTA, $\mathrm{pH}$ 8.0.50 mM $\mathrm{NaCl}$, and $0.5 \%$ SDS).

To examine the effects of incubation time in the proteinase $\mathrm{K}$ (prt $\mathrm{K}$ ) digestion buffer, two durations were tested (overnight and 72 hours). All samples were incubated at $55^{\circ} \mathrm{C}$ in a heating block, and samples were agitated every 3 hours during the day. Proteinase $\mathrm{K}$ was inactivated the next day or after 72 hours by incubation at $95^{\circ} \mathrm{C}$ for 1 hour.

\section{DNA Isolation}

DNA isolation was performed either with a commercially available kit (QIAamp DNA FFPE Tissue Kit, Qiagen, Duesseldorf, Germany) or with the phenol-chloroform method.

For phenol-chloroform (PC) extraction, equal volume of phenol (Merck KGaA, Darmstadt, Germany) was added and vortexed. After spinning for 3 minutes at $14000 \mathrm{rpm}$, the aqueous layer was transferred to a new tube. An equal volume of phenol-chloroform-isoamyl alcohol (25:25:1) (AppliChem, Inc. in New Haven, CT, U.S.A.) was added, and the product was vortexed and then spun for 5 minutes at $14000 \mathrm{rpm}$ in a microcentrifuge. The aqueous layer was transferred to a new tube. The estimated volume of the aqueous layer that was collected for DNA precipitation was $550 \mu \mathrm{l}$, and 0.1 volume of $3 \mathrm{M}$ sodium acetate and 1 volume of isopropanol were added. After thorough mixing, the tube was placed in a freezer for 30 minutes. The tube was then spun a maximum speed for 10 minutes at $4^{\circ} \mathrm{C}$ in a microcentrifuge. The supernatant was discarded, and the pellet was washed with $1 \mathrm{ml} 70 \%$ cold ethanol and spun at maximum speed for 10 minutes at $4^{\circ} \mathrm{C}$. The supernatant was discarded carefully, and the pellet dried, but 
care was taken to avoid over-drying. The pellet was then re-suspended with biological grade of $50 \mu \mathrm{l}$ $\mathrm{dH}_{2} \mathrm{O}$.

The manufacturer's instructions were followed for DNA isolation with the QIAamp DNA FFPE Tissue Kit. The final elution volume of $\mathrm{dH}_{2} \mathrm{O}$ was $50 \mu$.

\section{DNA Quantification}

The following tests were performed on all extracts:

- quantification of the concentration and purity of the DNA using a spectrophotometer (Nanodrop-8000, Thermo Fisher Scientific, USA);

- measurement of the DNA yield with a Quant-iT PicoGreen dsDNA BR assay (Invitrogen, Paisley, UK); and

- conventional PCR amplification of the 152, 258, and 564 bp human $\beta$-actin genomic DNA fragments (Alpha DNA, Montreal, Quebec).

For NanoDrop spectrophotometers, the appropriate A260:A280 ratio for assessing the purity of DNA is $\sim 1.80$. For the PicoGreen assays, a standard curve was used to determine the amounts of DNA.

$\beta$-actin fragments were amplified by PCR using the set of primers shown in table 1 . The final volume used in the PCR system was $50 \mu \mathrm{l}$, and this volume contained $5 \mu \mathrm{l}$ extracted DNA, 1u Taq DNA polymerase (Hopegen Biotechnology, Taiwan), $10 \mu \mathrm{M}$ of each primer, $2.5 \mu \mathrm{M} d N T P$ mix, and $\mathrm{dH}_{2} \mathrm{O}$. PCR was performed in a PCR sprint cycling system (Thermo Hybaid, Franklin, MA, U.S.) thermal cycler.

We examined the following groups of sections:

$\mathrm{A}_{1}$ : Deparaffinized in Tubes + Digested ON + Using Commercial Kit $(\mathrm{n}=4)$

$\mathrm{B}_{1}$ : Deparaffinized in Tubes + Digested $\mathrm{ON}+$ Using Phenol-chloroform $(n=4)$

$\mathrm{C}_{1}$ : Deparaffinized in Tubes + Digested 72 hours

+ Using Commercial Kit $(\mathrm{n}=4)$

$\mathrm{D}_{1}$ : Deparaffinized in Tubes + Digested 72 hours

+ Using Phenol-chloroform $(\mathrm{n}=4)$

$\mathrm{A}_{2}$ : Deparaffinized on Slide + Digested $\mathrm{ON}+$ Using Commercial Kit $(\mathrm{n}=4)$

$\mathrm{B}_{2}$ : Deparaffinized on Slide + Digested $\mathrm{ON}+$ Using Phenol-chloroform $(n=4)$

$\mathrm{C}_{2}$ : Deparaffinized on Slide + Digested 72 hours

+ Using Commercial Kit $(\mathrm{n}=4)$

$\mathrm{D}_{2}$ : Deparaffinized on Slide + Digested 72 hours
+ Using Phenol-chloroform $(\mathrm{n}=4)$

The University of Gazi Institutional Review Board approved the use of archival paraffin blocks for this study (09.06.2009-21/53).

\section{Statistical analysis}

All data are presented as the means and standard deviations (SDs) and are shown in table 2 . Three-way analyses of variance were used to assess the statistical significance of group differences, and the Statistical Package for the Social Sciences (SPSS version16.0.1) software package for Windows was used to perform these tests. P values below 0.05 were accepted as significant.

\section{Results}

We compared the DNA quantities (ng and $\mathrm{ng} / \mu$ ) and qualities (purity and amplifiability) that resulted from different methods of extraction from FFPE tissues of four cases per pairs.

\section{Assessment of the quantities of extracted DNA}

The results of the present study revealed that the DNA yields from FFPE tissues varied depending on the extraction method (Table 2). Group $C_{2}$ produced the greatest yield and highest concentration.

The results of the 3-way analyses of variance of yields and concentrations are given in table 3 .

Considering, only one of the three parameters (i.e., deparaffinization, digestion time, and isolation); the samples that were deparaffinized on slides produced greater DNA yields than did the samples that were deparaffinized in tubes $(p=0.011)$ regardless of the digestion duration and isolation method. However, the concentrations of nucleic acids produced from the samples that were deparaffinized in tubes were significantly higher than those of the samples that were deparaffinized on slides $(p=0.007)$.

It appears that digestion with prt $\mathrm{K}$ for duration longer than overnight improved the efficiency of DNA extraction from FFPE tissues when the commercial kit was used regardless of whether tubes or slides were used. Moreover, when PC extraction was used, overnight digestion produced greater amounts and higher concentrations of DNA regardless of which deparaffinization method $(p=0.018, p=0.019)$.

Table I: $\beta$-actin PCR primer sequences.

\begin{tabular}{lll}
\hline Primer & Forward & Reverse \\
\hline$\beta$-actin $564 \mathrm{bp}$ & CTGGGACGACATGGAGAAA & AAGGAAGGCTGGAAGAGTGC \\
$\beta$-actin $258 \mathrm{bp}$ & AGAAGGCTGGGGCTCATTTG & AGGGGCCATCCACAGTCTTC \\
$\beta$-actin152 bp & TGGGTTTCTGATAGGCACTGACT & AACAGCATCAGGAGTGGACAGAT \\
\hline
\end{tabular}


Table 2: Yields and purities of DNA extracted from FFPE tissues according to eight protocols.

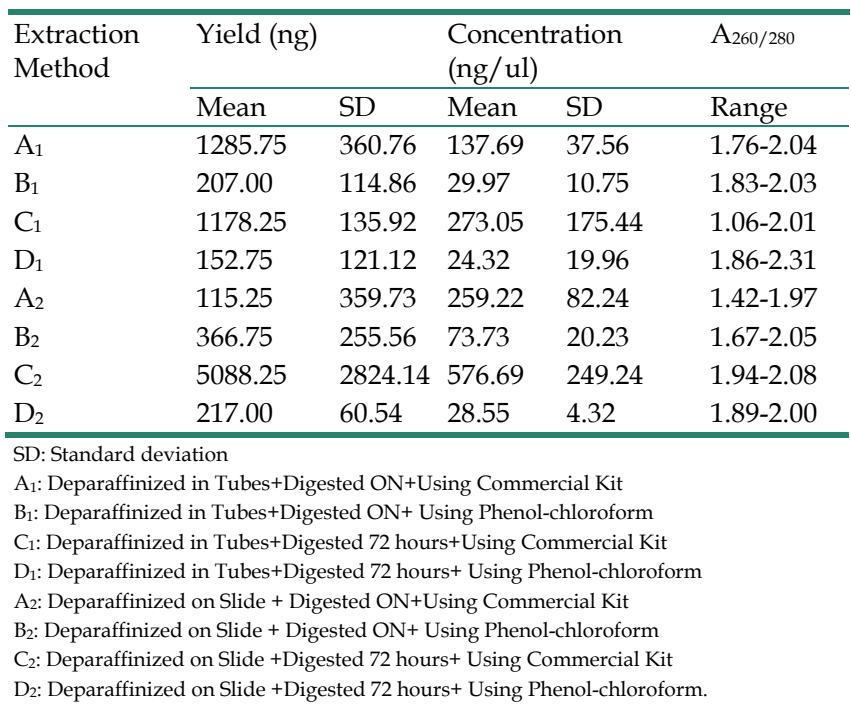

Table 3: The results of the 3-way analyses of variance of yields and concentrations.

\begin{tabular}{|c|c|c|}
\hline & Yield (ng) & $\begin{array}{l}\text { Concentration } \\
\text { (ng/ul) }\end{array}$ \\
\hline \multicolumn{3}{|l|}{ One-effect } \\
\hline Deparaffinization & $0.011^{*}$ & $0.007^{*}$ \\
\hline Digestion time & $0.018^{*}$ & $0.019^{*}$ \\
\hline Isolation & $<0.001^{*}$ & $<0.001^{*}$ \\
\hline \multicolumn{3}{|l|}{2 ways interaction } \\
\hline Deparaffinization-Digestion time & $0.011^{*}$ & 0.381 \\
\hline Deparaffinization- Isolation & $0.023^{*}$ & $0.027^{*}$ \\
\hline Digestion time- Isolation & $0.010^{*}$ & $0.004^{*}$ \\
\hline \multicolumn{3}{|l|}{3 ways interaction } \\
\hline $\begin{array}{l}\text { Deparaffinization-Digestion time- } \\
\text { Isolation }\end{array}$ & $0.008^{*}$ & 0.178 \\
\hline
\end{tabular}

Use of the commercial kit resulted in significantly greater DNA yields and higher concentrations than the PC method in all conditions $(p \leq 0.001)$.

Regarding the interactions effects between methods, significant better results, both in terms of yield and concentration, were produced by the samples treated with the commercial kit and 72 hours prt $\mathrm{K}$ digestion ( $p=0.010$ and $p=0.004$, respectively) compared to the samples that were digested overnight and isolated with the PC method. Furthermore, the samples that were deparaffinized on slides and isolated with the commercial kit produced significantly greater amounts and higher concentrations of DNA $(p=0.023$ and $p=0.027$, respectively). Similarly, deparaffinization on slides with 72 hours of digestion resulted in a greater amount of DNA $(p=0.011)$ but did not increase the concentration.

The greatest yield and highest concentration of
DNA was produced by the samples that were deparaffinized on slides, digested for 72 hours with Prt K and isolated with the commercial kit $(p=0.008$ and $p=0.007$, for yields and concentrations, respectively).The samples that were deparaffinized in tubes, digested $\mathrm{ON}$ and extracted with the phenol-chloroform method produced the lowest DNA yield, and the samples that were deparaffinized in tubes, digested for 72 hours and isolated using the phenol-chloroform method produced the lowest concentration.

\section{Assessment of the quality of the extracted DNA}

The purity of the extracted DNA was assessed as the ratio of the absorbance at $260 \mathrm{~nm}$ and $280 \mathrm{~nm}$ $\left(\mathrm{A}_{260 / 280}\right) . \mathrm{A}_{260 / 280}$ ratios between 1.8 and 2.0 indicate nearly protein-free DNA.

All samples isolated with phenol-chloroform method were of lower purity than those that were purified with the commercial kit $(p=0.036)$.

The different deparaffinization methods also affected the amplifiability of the extracted DNA. Based on PCR amplification performance, the samples that were isolated with the commercial kit produced better results. PCR amplification of the $152 \mathrm{bp} \beta$-globin gene fragment produced positive results in all samples. However, $75 \%$ and $50 \%$ of all samples were positive for the amplification of the $258 \mathrm{bp}$ and $564 \mathrm{bp} \beta$-globin gene fragments, respectively. The amplification rate for the 564-bp $\beta$-globin gene fragment among the samples that were isolated with the commercial kit was $80 \%$ (n:12), whereas only 4 samples (25\%) of PC isolation group were positive for 564 -bp $\beta$-globin gene.

The samples in which the 564 bp beta-globin was amplified were from groups $A_{2}$ and $C_{2}$. Although the rates of the positive detection of gene fragments did not vary significantly across groups, the best results were obtained from groups $A_{1}, C_{1}$, and $C_{2}$.

\section{Discussion}

Since 1984, several human tissue banks have been available to researchers in the field of molecular biology in the USA [9-11]. The goal of these procurement organizations is primarily to provide tissues to researchers seeking to screen for genetically based diseases and the genetic bases of diseases. Nevertheless, multiple factors affect the molecular profiles of cells. These factors that affect these profiles in FFPE tissues include pre-fixation time, the properties of the fixatives, the conditions of the fixative, and the post-fixative storage parameters. The main goal is to preserve nucleic acids in diagnostic specimens for the identification of specific diagnostic and prognostic 
molecular targets [12].

In biomedical science, the human tissues that researchers receive are nearly always tissues that remain after routine diagnostic procedures. Worldwide, the most commonly used fixative agent for these tissues is formalin (HCHO). Formalin is an agent that forms crosslinks between the lysine groups of amino acids. Despite formalin's effect on nucleic acids, it is still the principal fixative of the practice of pathology [13].

The goal of current study was to clarify the optimal method of DNA extraction from FFPE tissues by comparing different deparaffinization procedures, Prt $\mathrm{K}$ digestion durations, and isolation methods.

In this study, we focused on different steps of the DNA extraction procedure. Our results indicated that the deparaffinization procedure had the largest effect $(p=0.011)$. Efficient deparaffinization also aids in the removal of residues that may affect amplification. Lin et al reported the use of mineral oil to remove wax from FFPE samples [1]. Automated systems use heat and magnetization [3]. But still the most common pretreatment technique is xylene (a strong solvent) and ethanol washing [8]. It is well-known that formaldehyde does not completely degrade nucleic acid but does, however, produce cross-linkages. Several authors have shown that heating FFPE samples improves the efficiency of DNA extraction $[2,14]$. The cross-linking of proteins to nucleic acids is thought to be heat-reversible $[15,16]$. We used a temperature of $56^{\circ} \mathrm{C}$ in a standard incubator for deparaffinization with the aim of melting paraffin onto the slides prior to xylene treatment. Shi et al showed that the use of high-pH solutions, such as $0.1 \mathrm{M} \mathrm{NaOH}$ or $\mathrm{KOH}$, while heating the samples to approximately $100^{\circ} \mathrm{C}$ plays a critical role in this process $[2,14]$.

On the other hand, deparaffinization on slides also allows for the macrodissection of desired portions of the tissue. Furthermore, this method is much easier, more efficient and less time consuming compared to dewaxing in 1.5 or $2 \mathrm{ml}$ tubes. Therefore, we suggest deparaffinization on slides with xylene and ethanol treatment after warming the tissues to a temperature that does not harm nucleic acids.

It is well-known that ethanol-based fixatives or acetone produce less DNA damage than formaldehyde $[13,17]$. Although the histological detail resulting from the use of these fixatives is poor, in two studies, Greer et al showed that 95\% ethanol and acetone produce superior amplification results than $10 \%$ formaldehyde with both short- and long-term fixations. Because $10 \%$ formalin remains the most widely used fixative, further studies focusing on minimizing the chemical reactions between nucleic acids and formaldehyde will be more appreciated. Several studies have indicated that low temperatures $\left(4^{\circ} \mathrm{C}\right)$, neutrally buffered formaldehyde, the fixing of small volumes of tissues, and short fixation times (3 to 6 hours) decrease the extent of DNA harm [12, 18-21].

The enzymatic digestion step is undoubtedly one of the most important steps in the DNA extraction procedure. Nevertheless, an accepted, universally used protocol does not exist. We agree that the enzyme volume-cell number ratio is critical. Prt $\mathrm{K}$ is an enzyme that is widely used for protein digestion. Digestion periods can be prolonged for up to 5 days until the tissues are fully dissolved. The current study found statistically significant evidence that longer digestion periods produce greater amounts and higher concentrations of DNA $(p=0.018, p=0.019$, respectively). One-hour and overnight digestions have been used in several previous studies [4, 7, 22], but experienced laboratories acknowledge the fact that prolonged protein digestion times dramatically increase DNA yields [5, 23-25]. Diaz-Cano and Brady reported that $\beta$-globin amplification of samples digested for 5 days produces sharper bands [25]. The hypothesis underlying the extension of enzymatic digestion is that the cross-links are reversed by heat and that this reversal can be enhanced either by increasing the incubation temperature or the incubation time $[14,16,23,26]$. Because high temperatures induce the degradation of DNA itself, prolongation of the duration would seem to be the more beneficial approach.

Phenol-chloroform (PC) extraction is a liquid-liquid extraction that has been used for in the isolation of DNA, RNA, and proteins, particularly for blood samples. The use of PC isolation, with minor modifications, for FFPE tissues has been recommended by several studies [5, 25]. In the current study, we used a previously described PC isolation protocol [5]. We found that reduced DNA concentrations were obtained from the PC groups $(p<0.001)$ compared to the groups that were cleaned with the commercial kit. Although no statistically significant differences in PCR amplification were found between the PC protocol and the commercial kit, the samples from which 564 bp beta-globin was amplified were from the $\mathrm{A}_{2}$ and $\mathrm{C}_{2}$ groups. Various PCR amplification rates have been reported in the literature. Similar to the results of the current study, Gillio-Tos et al reported increased amplification rates of short amplicons [27]. Santos et al performed DNA extraction from FFPE tissue using an automatic nucleic acid isolation system and reported a $60 \%$ amplification rate of a 1182 base pair fragment [7], whereas, in our study, the amplification rate for the 564-bp $\beta$-globin gene fragment among the samples that were isolated with the commercial kit was $80 \%$ (n:12). The widespread use of 
silica-based membrane commercial kits has reduced their price in recent years, these kits are easy to use, and they require fewer biohazardous ingredients compared to organic extraction methods.

To the best of our knowledge, only one study has reported on the use of a combined PC and silica-based spin column extraction method; however, minimization of the manipulation required across the entire process has been suggested to improve PCR efficiency. Shi et al combined deparaffinization and digestion using high-pH buffers and heat $[2,14]$; however, the resulting PCR products were smaller than $350 \mathrm{bp}$, and the purity of the DNA was questionable. The successful amplification of DNA from FFPE tissues via different extraction methods has been demonstrated in several reports $[7,28,29]$.

\section{Conclusion}

The results of our study indicated that the most important steps were deparaffinization and isolation. Paraffin remnants reduce the quality and quantity of the samples. It is unlikely that formalin will be replaced with another fixative because current morphological diagnoses depend on FFPE and hematoxylin-eosin-stained samples. Although non-formalinbased molecular fixatives and novel processing techniques can produce high quality nucleic acid, the main goal of all researchers in this field, us included, is to find a user-friendly, cost effective, less hazardous, simple method of extracting DNA from archival FFPE tissues. Silica-based commercial kits and automated systems should be considered for DNA extraction from FFPE samples in the place of traditional organic methods.

\section{Acknowledgement}

This study was funded by Gazi University Scientific Research Commity (03-2010/05).

\section{Competing Interests}

The authors have declared that no competing interest exists.

\section{References}

1. Lin J, Kennedy SH, Svarovsky T, Rogers J, Kemnitz JW, Xu A, Zondervan KT: High-quality genomic DNA extraction from formalin-fixed and paraffin-embedded samples deparaffinized using mineral oil. Anal Biochem 2009, 395:265-267

2. Shi SR, Datar R, Liu C, Wu L, Zhang Z, Cote RJ, Taylor CR: DNA extraction from archival formalin-fixed, paraffin-embedded tissues: heat-induced retrieval in alkaline solution. Histochem Cell Biol 2004, 122:211-218.

3. Hennig G, Gehrmann M, Stropp U, Brauch H, Fritz P, Eichelbaum M, Schwab $\mathrm{M}$, Schroth W: Automated extraction of DNA and RNA from a single formalin-fixed paraffin-embedded tissue section for analysis of both single-nucleotide polymorphisms and mRNA expression. Clin Chem 2010, 56:1845-1853.

4. Huijsmans CJ, Damen I, van der Linden JC, Savelkoul PH, Hermans MH: Comparative analysis of four methods to extract DNA from paraffin-embedded tissues: effect on downstream molecular applications. BMC Res Notes 2010, 3:239.
5. Pikor LA, Enfield KS, Cameron H, Lam WL: DNA extraction from paraffin embedded material for genetic and epigenetic analyses. J Vis Exp 2011.

6. Greer CE, Lund JK, Manos MM: PCR amplification from paraffin-embedded tissues: recommendations on fixatives for long-term storage and prospective studies. PCR Methods Appl 1991, 1:46-50.

7. Santos S, Sa D, Bastos E, Guedes-Pinto H, Gut I, Gartner F, Chaves R: An efficient protocol for genomic DNA extraction from formalin-fixed paraffin-embedded tissues. Res Vet Sci 2008.

8. Goelz SE, Hamilton SR, Vogelstein B: Purification of DNA from formaldehyde fixed and paraffin embedded human tissue. Biochem Biophys Res Commun 1985, 130:118-126

9. Clausen KP, Grizzle WE, Livolsi V, Newton WA, Jr., Aamodt R: Special communication. The Cooperative Human Tissue Network. Cancer 1989, 63:1452-1455.

10. LiVolsi VA, Clausen KP, Grizzle W, Newton W, Pretlow TG, 2nd, Aamodt R: The Cooperative Human Tissue Network. An update. Cancer 1993, 71:1391-1394.

11. Jewell SD, Srinivasan M, McCart LM, Williams N, Grizzle WH, LiVolsi V, MacLennan G, Sedmak DD: Analysis of the molecular quality of human tissues: an experience from the Cooperative Human Tissue Network. Am J Clin Pathol 2002, 118:733-741.

12. Srinivasan M, Sedmak D, Jewell S: Effect of fixatives and tissue processing on the content and integrity of nucleic acids. Am J Pathol 2002, 161:1961-1971.

13. Ben-Ezra J, Johnson DA, Rossi J, Cook N, Wu A: Effect of fixation on the amplification of nucleic acids from paraffin-embedded material by the polymerase chain reaction. J Histochem Cytochem 1991, 39:351-354.

14. Shi SR, Cote RJ, Wu L, Liu C, Datar R, Shi Y, Liu D, Lim H, Taylor CR: DNA extraction from archival formalin-fixed, paraffin-embedded tissue sections based on the antigen retrieval principle: heating under the influence of $\mathrm{pH}$. J Histochem Cytochem 2002, 50:1005-1011.

15. Shi SR, Cote C, Kalra KL, Taylor CR, Tandon AK: A technique for retrieving antigens in formalin-fixed, routinely acid-decalcified, celloidin-embedded human temporal bone sections for immunohistochemistry. J Histochem Cytochem 1992, 40:787-792.

16. Solomon MJ, Varshavsky A: Formaldehyde-mediated DNA-protein crosslinking: a probe for in vivo chromatin structures. Proc Natl Acad Sci U S A 1985, 82:6470-6474.

17. Greer CE, Peterson SL, Kiviat NB, Manos MM: PCR amplification from paraffin-embedded tissues. Effects of fixative and fixation time. Am J Clin Pathol 1991, 95:117-124.

18. Fedorowicz G, Guerrero S, Wu TD, Modrusan Z: Microarray analysis of RNA extracted from formalin-fixed, paraffin-embedded and matched fresh-frozen ovarian adenocarcinomas. BMC Med Genomics 2009, 2:23.

19. Bramwell NH, Burns BF: The effects of fixative type and fixation time on the quantity and quality of extractable DNA for hybridization studies on lymphoid tissue. Exp Hematol 1988, 16:730-732.

20. Douglas MP, Rogers SO: DNA damage caused by common cytological fixatives. Mutat Res 1998, 401:77-88

21. Williams C, Ponten F, Moberg C, Soderkvist P, Uhlen M, Ponten J, Sitbon G, Lundeberg J: A high frequency of sequence alterations is due to formalin fixation of archival specimens. Am J Pathol 1999, 155:1467-1471.

22. Oh SY, Kim WY, Hwang TS, Han HS, Lim SD, Kim WS: Development of an ammonium sulfate DNA extraction method for obtaining amplifiable DNA in a small number of cells and its application to clinical specimens. Biomed Res Int 2013, 2013:546727.

23. Isola J, DeVries S, Chu L, Ghazvini S, Waldman F: Analysis of changes in DNA sequence copy number by comparative genomic hybridization in archival paraffin-embedded tumor samples. Am J Pathol 1994, 145:1301-1308.

24. Wood HM, Belvedere O, Conway C, Daly C, Chalkley R, Bickerdike M, McKinley C, Egan P, Ross L, Hayward B, et al: Using next-generation sequencing for high resolution multiplex analysis of copy number variation from nanogram quantities of DNA from formalin-fixed paraffin-embedded specimens. Nucleic Acids Res 2010, 38:e151.

25. Diaz-Cano SJ, Brady SP: DNA extraction from formalin-fixed, paraffin-embedded tissues: protein digestion as a limiting step for retrieval of high-quality DNA. Diagn Mol Pathol 1997, 6:342-346.

26. Gilbert MT, Haselkorn T, Bunce M, Sanchez JJ, Lucas SB, Jewell LD, Van Marck E, Worobey M: The isolation of nucleic acids from fixed, paraffin-embedded tissues-which methods are useful when? PLoS ONE 2007, 2:e537.

27. Gillio-Tos A, De Marco L, Fiano V, Garcia-Bragado F, Dikshit R, Boffetta P, Merletti F: Efficient DNA extraction from 25-year-old paraffin-embedded tissues: study of 365 samples. Pathology 2007, 39:345-348.

28. Noguchi M, Furuya S, Takeuchi T, Hirohashi S: Modified formalin and methanol fixation methods for molecular biological and morphological analyses. Pathol Int 1997, 47:685-691.

29. Yagi N, Satonaka K, Horio M, Shimogaki H, Tokuda Y, Maeda S: The role of DNase and EDTA on DNA degradation in formaldehyde fixed tissues. Biotech Histochem 1996, 71:123-129. 